\title{
Editorial
}

\section{Melissa Layne}

American Public University System

Dear SESA Readers,

7 he inaugural 2020 Space Education \& Strategic Applications conference in October was certainly a testament to perseverance and commitment. Originally scheduled six months earlier in April as an in-person event, organizers were forced to postpone the conference to October using a virtual platform. Despite this rapid and dynamic pivot to hold a virtual conference, our sponsors, American Public University System (APUS) and Policy Studies Organization (PSO), were well-equipped to rise to the occasion. However, we were careful not to be too sure of ourselves lest something terribly wrong were to occur!

As the conference date was nearing, we continued to experience an increasing influx of presentations; so, what was supposed to be a one-day event, now became two full days for the space community to gather in "our virtual space."

Dr. Vernon Smith, Provost at APUS, served as our Master of Ceremonies by opening the conference with a lively and motivational introduction, and ended by expressing sincere gratitude to presenters, attendees, and organizers. Our presenters shared their extensive knowledge around a variety of space-related topics via sessions, roundtables, panels, fireside chats, and keynotes. As a newcomer to the space conference scene, SESA's plenary addresses were quite impressive, and included NASA's Julielynn Wong, Stacy Kubicek from Lockheed Martin, Natalie Panek of Mission Systems MDA, and Emily Calandrelli, host of the Emily's Wonder Lab. The most anticipated session was that of the Honorable Barbara Barrett, Secretary of the U.S. Air Force. For session video recordings go to https://whova. com/embedded/event/seasa_202010/?utc_source=ems

This issue highlights the truly outstanding work from some of our presenters-many of whom have expressed their excitement for the next SESA conference taking place on September $23^{\text {rd }}$ and $24^{\text {th }}, \mathbf{2 0 2 1}$. Mark your calendars!

The following pages provide a glimpse of some of our conference data in addition to attendee / presenter responses to our end-of-conference survey.

Melissa Layne, Ed.D.

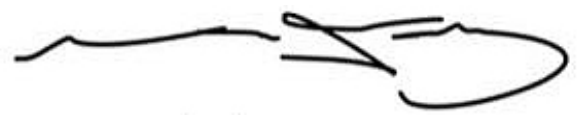

Editor-in-Chief, SESA 